\title{
Calculations of compressed rods considering experiments over last 100 years
}

\author{
Denis Konin* \\ Research Institute of Building Constructions (TSNIISK) named after V.A. Koucherenko, 2nd \\ Institutskaya st., Moscow, 109428, Russia
}

\begin{abstract}
The article presents the results of testing and FE-modelling of rods calculated for the central and eccentric compressive load. More than 600 tests have been analysed over the past 100 years, including made by author, in a wide range of slenderness made of steels with a yield strength of up to $1000 \mathrm{MPa}$. It is established that the existing Russian calculation methods allow us to accurately determine the bearing capacity of the rod for steel of any strength. Verification of calculation method was carried out not only by stresses and ultimate load-bearing capacity, but also by the deformations of the tested rods. It is established that for H-beams and thinwalled pipes, clarification of the design codes is required to be able to design cost-effective designs, since the code formulas give a margin. This is especially true for elements of low flexibility with small eccentricities. To clarify the codes, a method for modelling a three-line diagram of steel operation, verified with the test results, is proposed.
\end{abstract}

\section{Introduction}

At the beginning of the 20th century and earlier, analytical, and experimental methods were used to justify the reliability of building structures. The development of computer technologies allows to perform many calculation options without resorting to expensive experiments. When computer modelling of steel rods compressed with bending, it is necessary to consider initial eccentricities and bends, uneven distribution of material properties over the cross section, residual stresses, etc. The influence of these random factors (imperfections) on the stress-strain state of the compressed rod can only be determined by experimental studies [1-5]. Considering random factors is necessary, both when calculating individual rods, and when modelling complex multidimensional structures.

The influence of imperfections in codes for the calculation of structures is considered by the integral coefficient of longitudinal bending $\varphi$. In codes of Russia (SP 16.13330.2017 "Steel structures"), European Union (Eurocode 3: Design of steel structures) and PRC (GB50017-2003 Code for design of steel structures) for various cross-sections, there are three main curves of the longitudinal bending coefficient. The most detailed classification of cross-sections for different types of cross-sections is given in the EU codes. Codes of the

* Corresponding author: konden@inbox.ru 
United States (ANSI/AISC 360-16 An American National Standard. Specification for Structural Steel Buildings) require the calculation of the rods for compression on a single curve. Eurocode 3 has two additional curves $a_{0}$ and $d$, which are designed to consider the effect of modern high-strength S460 steels (curve $a_{0}$ ), as well as the negative effects of appearance of residual stresses in welded I-beams. Russian codes do not consider the type of hot-rolled profile (H or I) and features of production of high-strength steel I-beams. In addition, there is no difference in the calculation of the welded or rolled I-beam. A positive point can be considered that SP 16.13330 has no restrictions on the use of steels, while in Eurocode 3 a strict list is given, limited to S460. Also, $\varphi$-data in SP 16.13330.2017 for the same types of cross sections with the same external eccentricities, different results of the calculation of the load-bearing capacity are obtained. The discrepancy between the curves of "centrally" and "eccentric" compressed rods is at small relative eccentricities $(m)$ : for $\bar{\lambda}<3$ is a difference of $3-5 \%$, and for $\bar{\lambda}>6-$ more than $20-30 \%$.

This work solves the following problems: to assess the impact of new steels (yield strength of $500 \mathrm{MPa}$ or more) on the operation of the rods during compression, to correct some inconsistencies in the Russian standards, to consider the test results for the last 100 years.

\section{Methods}

\subsection{Tests performed by author}

In 2016, to establish the reliability of the longitudinal bending coefficients given in Russian and other codes, tests were carried out for eccentric compression of 12 rods. Rods were made of steel 14G2AF-1 (6 pcs.) and 17G1SANF (6 pcs.) in form of hot-rolled H-beams 40K2 (GOST R 57837, column type). The steel used is the closest to the steel C440 (GOST 27772-2015) and had a strength $\sigma_{0,2}=481 \mathrm{MPa}$.

Test models are designed as rods with slenderness from 16 to $35(\bar{\lambda}=0.7 \ldots 1.6)$. The relative eccentricity $m=(1.6,4.8)$ was modeled. It was applied both in the plane of web (strong axes - SA) and in the plane of flanges (weak axes - WA, see Figure 1). Prior to the tests, all models of columns were carefully measured, and detailed studies of the steels for weldability, cold resistance, and actual strength values, depending on sample location (for more information, see [6, 7]). Maximum initial deflection was found in model K1.1 and equals $1 / 1650 * \mathrm{~L}$ (in plane of flanges); average deflection was negligible little $(1 / 3400 * \mathrm{~L}=0,0003 * \mathrm{~L})$ due to the significant size of the H-beam. Models were mounted on knife supports, which modeled the hinge attachment in plane in which eccentricity was modeled. To confirm the accuracy of the test results, as well as to exclude the influence of random factors (hinge jamming, incorrect centering, measurement errors), the model of each length $(331,357,395,405 \mathrm{~cm}$ between axes of the knife supports) was tested in two copies for the corresponding eccentricity.

The tests were carried out with a press MAN1000 with a maximum compressive load of $10 \mathrm{MN}$. During the tests it was measured on every load step (see Figure 1): deflections in two planes (by D1, D2, D3), shortening and ends rotation (by S1, S2, S3, S4) and maximum flanges strain (by $\mathrm{T} 1 \ldots \mathrm{T} 8$ ). 


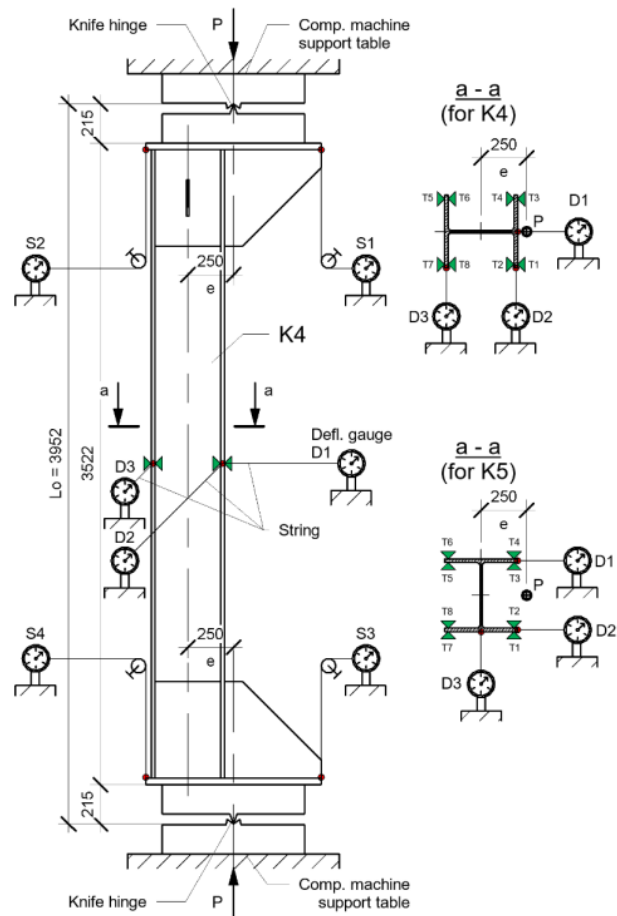

Fig. 1. Diagram of the test facility with the K4 model
During the experiment, the loss of local stability in flange and walls was not observed. There was a uniform onset of yield strength in most compressed fibers, fixed by strain gages $(T)$. On the surfaces of each model (previously treated with talc), traces in the form of dark ChernovLüders lines appeared in characteristic places. Both with strain gages it indicates that the yield strength has been reached (Figure 2). It was also recorded by the strain-measuring complex and the increase in deflections in the force plane. At the onset of yield strength in $60-70 \%$ of the cross-section, the tests were stopped.

In 2017 , to study the features of the operation of spiral-welded and straightwelded pipes for structures, a set of tests for central and eccentric compression of 23 rods was carried out (more detailssee [8]). During the experiment, fiber deformations in cross-sections, bends, and forces corresponding to local or general loss of stability were obtained.

Also, a statistically reliable diagram of the steel performance of the studied pipes was obtained.

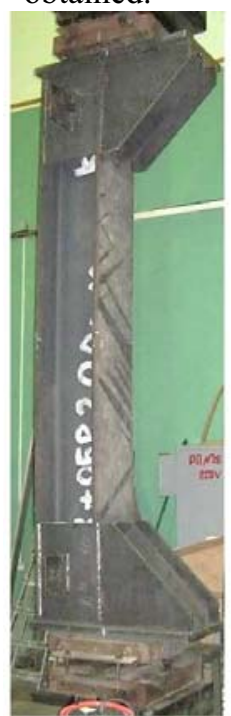

a)

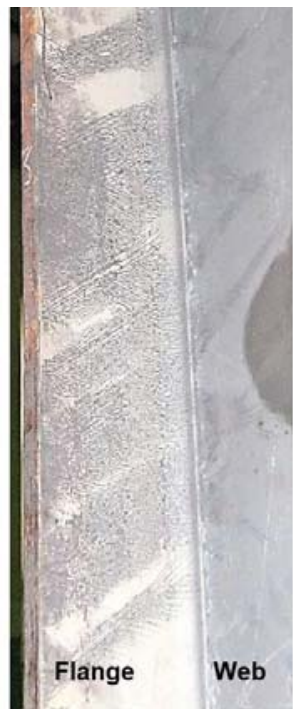

b)

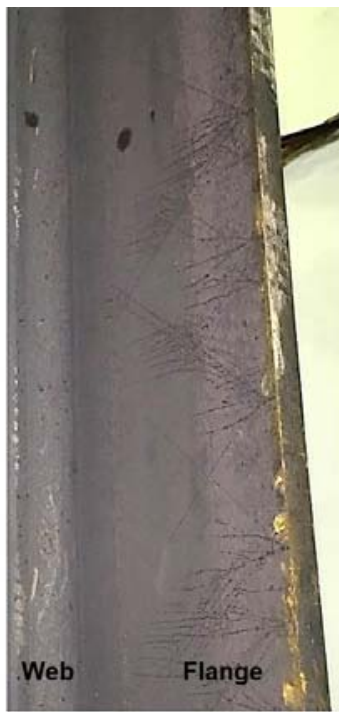

c)

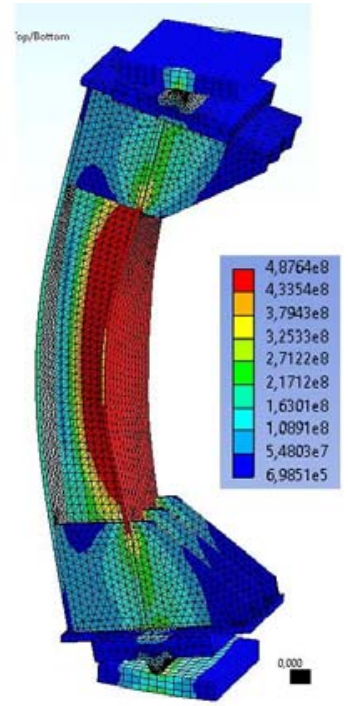

d)

Fig. 2. Model K3.1 after test with Chernov-Lüders lines $(a)$, inner surface K3.1 $(b)$, inner surface K5.2 (c), FE-model appropriate K1.1 (d) 


\subsection{Tests performed by other researchers}

Most important experimental and theoretical studies of steel rods over the past 100 years are the following. Many of the considered works are "classical" and their results once formed the basis of modern codes for design of structures. A significant number of authors referred to the experiments of M. Roche [9] of 1927-1928 and used them to justify their own research on bearing capacity of compressed rods. USA Codes for calculating compressed rods were formed under the influence of A. Stang [10] experiments in 1936, B. Johnston and L. Cheney [11, 12, 13] in 1939-1942. A. Stang [10] studied the work on compression of large complex columns with low slenderness. B. Johnston and L. Cheney $[11,12,13]$ conducted representative compression tests of 113 hot-rolled I-beams of low slenderness too. In USSR, a set of representative tests was performed by A.V. Gemmerling and his co-authors. In [1, 2] summarize the results of several tests conducted in 1939-1949 for the construction of The Palace of Soviets and the building of the Moscow State University. In [4] of 1961 fundamental studies of compressed and bended rods with rectangular cross-section were performed, including in the composition of complex structures - frames and trusses (44 pcs.). A large experiment to study the operation of compressed-curved rods was performed by TsNIIPSK [3] under the leadership of N. P. Melnikov in 1954-1960. 120 rods were tested including biaxial eccentricity of the load. G. M. Chuvikin [14] in 1960 presented a series of tests of 20 welded I-beams for biaxial eccentricity. G. E. Belsky and L. N. Dionisiadi [18] conducted studies of the operation of thin-walled electric-welded pipes for off-centre compression and tension (12 pcs.). In [19] by A.M. Rivkin and G.E. Belsky electro welded pipes (38 pcs.) were studied. Fundamental studies of the operation of eccentrically compressed rods were carried out by prof. G. I. Bely and his students in 1980s [5]: 42 aluminium I-beam rods, 36 hollow section under biaxial eccentricity. These works [3, 14, 18, 19, 5] are the basis of modern Russian codes for structures calculation. Also of undoubted interest are the results of European studies: K. Kleppel and E. Winkelman [15] in 1962 (27 I-beams with biaxial eccentricities); K. Birnstil [16] in 1963 (20 I-beams with biaxial eccentricity and different end eccentricities). In USA, E. P. Popov in 1977 [17] tested for compression 5 large hot-rolled column profiles $\left(t_{f}=33\right.$ $\mathrm{mm}$ ). All the tests presented above (except for the tests of pipe profiles made in the USSR) were carried out using steels with a pronounced yield point and a zone of elastic-plastic deformations. Tests of rods made of steel with a yield strength of more than $390 \mathrm{MPa}$ were not performed at all until the 1980s due to the lack of appropriate steel for construction.

One of the first experiments of compressed rods made using high-strength steel was performed by T. Yusami, Yu. Fukumoto and other co-authors [20, 21, 22] in $1981 \ldots 1984$ (30 pcs., $R_{y}=750 \mathrm{MPa}$ ). The experiments of K. Rasmussen and co-authors [23] carried out in 1995 for 6 welded box and 5 welded I-beam profiles with $R_{y}$ up to $720 \mathrm{MPa}$. It was established that elements made of high-strength steels serve more efficiently due to a more favorable distribution of residual stresses, compared to "conventional" steels. Tests G. Shi and H. Ban, presented in [24], were among the first in 2012 conducted experiments eccentrically compression for 8 rods made of steels S690 and S960 $\left(R_{y}\right.$ from 800 to 1000 $\mathrm{MPa}$ ). It was proposed to use the most "cost-saving" curve $a_{0}$ by Eurocode 3 for these steels. In the work of H. Ban [25] also from 2012, 12 box-shaped welded columns made of S460 steel and 7 I-beams were tested. Based on the results of the experiment [25], finite element models were constructed, and the calculation results were compared with the curves of the longitudinal bending coefficient for the corresponding profile types according to Eurocode 3, ANSI/AISC 360-10, and the PRC - GB50017-2003 standard. The simulation of the steel was performed using a four-line diagram that considers the hardening of steel after overcoming yield strength. The change in Young modulus in the zone of elastic-plastic deformations was not considered, and the yield area was assumed without a slope. The next experiment, presented in [26], contains tests of 3 box-shaped and 
3 I-beam profiles made of steel with a yield strength of $960 \mathrm{MPa}$. The search for the optimal curve for calculating centrally compressed rods made of high-strength steels was also performed in the works of Y.B. Wang and co-authors [27, 29] and other researchers $[31,32]$. Tests of box and I-beam columns made of steel with an $R_{y}$ more than $770 \mathrm{MPa}$ were also carried out under the supervision of T.G. Lee [30] in 2016. The authors [30] determined that for welded box sections made of studied steel, the use of the curve with Eurocode 3 to is "very conservative" and it is recommended to use the curve $a$, as for more efficient sections (rolled I-beams). The only curve in the US standards is also recognized by the authors [30] as "conservative", not realizing the potential of using high-strength steels. Further, the same conclusions were confirmed in subsequent works by performing numerical calculations of many rods with modeling of residual stresses, different stiffness of the pinched ends. The properties of steel in [30]are modeled by a two-line diagram.

In total, the author of current article analyzed data on 656 tests. Considering the significant cost and complexity of the experiments, the authors, as a rule, test up to 10 rods, and more often $-6-8$ pieces. This complicates the analysis due to the difference in the equipment used, in the methods of applying boundary conditions, loading speed, and ends fixing. Many tests were planned incorrectly and were not included in this review at all. In the "bad" tests, the destruction occurred in the places where the supporting parts of the rods were crushed or there was a significant local buckling of the webs and flanges. This was due to non-compliance with limits on slenderness of webs and flanges.

\section{Results}

\subsection{Calculation by codes and FE-modelling}

The calculation of rod stability in the absence of eccentricity is performed in accordance with SP 16.13330 according to the formula:

$$
N / \varphi A R_{y} \gamma_{\mathrm{c}} \leq 1
$$

where $A, R_{y}$ - accordingly, the cross-sectional area and yield strength of the steel, $\gamma_{\mathrm{c}}-$ coefficient of the working conditions of the calculated element (in the future, we will take 1.0). Coefficient $\varphi$ determined by the formula:

$$
\varphi=0.5\left\{\left[9.87(1-\alpha+\beta \bar{\lambda})+\bar{\lambda}^{2}\right]-\sqrt{\left[9.87(1-\alpha+\beta \bar{\lambda})+\bar{\lambda}^{2}\right]^{2}-39.48 \bar{\lambda}^{2}}\right\} / \bar{\lambda}^{2}{ }_{(2)}
$$

where $\alpha$ и $\beta$ - coefficients depending on the type of cross-section.

The calculation of rod stability for eccentric compression with a cross section with two axes of symmetry in SP 16.13330 is performed by the formula:

$$
N / \varphi_{e} A R_{y} \gamma_{\mathrm{c}} \leq 1
$$

The $\varphi_{e}$ coefficient is determined from Table D.3 for various values of relative eccentricity $m_{e f}$ (from 0.1 to 20 ) and slenderness $\bar{\lambda}=L / i \cdot \sqrt{R_{y} / E}$. Relative eccentricity is calculated by the formula:

$$
m_{e f}=\eta \frac{M A}{N W}
$$

where $\mathrm{M}$ and $\mathrm{N}$ - are the bending moment and the longitudinal force; $\mathrm{W}$ - is the crosssection resistance moment for the compressed fiber. The coefficient of influence of the cross-sectional shape $\eta$ considers transition from the "standard" rectangular one to I-shaped or or another form. Coefficient $\eta$ need as a table with $\varphi_{e}$ in SP 16.13330 computed for a rectangular section. For such cross-section $\eta=1$. For the remaining sections, $\eta$ is determined by the formulas in Table 1 .

The values of these coefficients $\eta$ were determined by the authors [28] and included in Russian codes. The calculations were carried out iteratively, considering the elastic-plastic deformations of the steel (according to the tangential modulus $E_{t}$ ). Therefore, it would not 
be quite correct to check these coefficients using a two-line Prandtl diagram of the steel during FE-modelling.

Table 1. Coefficient $\eta$

\begin{tabular}{|c|c|c|c|c|c|}
\hline \multirow{3}{*}{\multicolumn{2}{|c|}{$\begin{array}{l}\text { Section type } \\
\text { (acc. SP 16) }\end{array}$}} & \multirow{4}{*}{$\begin{array}{c}A_{f} / A_{w} \\
-\end{array}$} & \multicolumn{3}{|l|}{$\eta$} \\
\hline & & & \multicolumn{2}{|l|}{$\bar{\lambda} \leq \mathbf{5}$} & \multirow{3}{*}{$\begin{array}{c}\bar{\lambda}>\mathbf{5} \\
1.1\end{array}$} \\
\hline & & & $0,1 \leq m \leq 5$ & $\mathbf{5} \leq \boldsymbol{m} \leq \mathbf{2 0}$ & \\
\hline 4 & $\circ \quad \square$ & & $(1.35-0.05 m)-0.01(5-m) \bar{\lambda}$ & 1.1 & \\
\hline \multirow{3}{*}{5} & \multirow{3}{*}{ I } & 0.25 & $(1.45-0.05 m)-0.01(5-m) \bar{\lambda}$ & 1.2 & 1.2 \\
\hline & & 0.5 & $(1.75-0.10 m)-0.02(5-m) \bar{\lambda}$ & 1.25 & 1.25 \\
\hline & & $\geq 1$ & $(1.90-0.10 m)-0.012(6-m) \bar{\lambda}$ & $1.4-0.02 \bar{\lambda}$ & 1.3 \\
\hline \multirow{3}{*}{8} & \multirow{3}{*}{$H$} & 0.25 & $(0.75+0.05 m)+0.01(5-m) \bar{\lambda}$ & 1 & 1 \\
\hline & & 0.5 & $(0.50+0.10 m)+0.02(5-m) \bar{\lambda}$ & 1 & 1 \\
\hline & & $\geq 1$ & $(0.25+0.15 m)+0.03(5-m) \bar{\lambda}$ & 1 & 1 \\
\hline
\end{tabular}

Although $\varphi$ and $\varphi_{e}$ have the same meaning, they are differing significantly in determination way. The coefficient $\varphi_{e}$ "includes" the effect of bending moment (eccentricity). This approach in determining of coefficient $\varphi_{e}$ is somewhat different from those adopted in Eurocode 3 and the US standards. Stability calculation under compression with an eccentricity in these codes, uses the same coefficient as for calculating the "central" compression, and the moment is considered directly in the formula when determining the stresses.

In order to demonstrate the effect of steel work in zone of elastic-plastic deformations, we modeled the simplest rod of rectangular cross-section (Figure $3 b$ ). It was calculate 134 rods with different slederness (from 1 to 5 ) and with different eccentricities $m_{e f}$ from 0.1 to 5 using ANSYS. The diagram shows that when calculating rods taking into account the two-line diagram (colored dotted lines), the value $\varphi_{e}$ significantly deviates upwards from the curve calculated according to SP 16.13330 (the maximum for small eccentricities $m_{e f}=0.1$ is about $12-13 \%$ ) and three-line diagram calculations. Than greater the $m_{e f}$, that the difference in results between calculations with two-line diagram and three-line one (solid-colored lines) and the SP (gray dotted line) smaller. That is, the calculation of the two-line diagram overestimates the values of $\varphi_{e}$ compared to the calculation of the threeline diagram. This circumstance should be taken into account for calculations of heavily loaded columns, for example, columns of high-rise buildings, where the eccentricities are small and an accurate determination of the maximum load-bearing capacity is necessary for rational design.

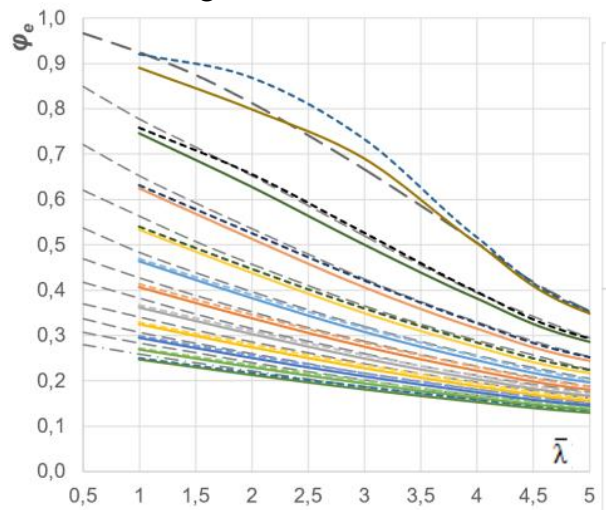

a)
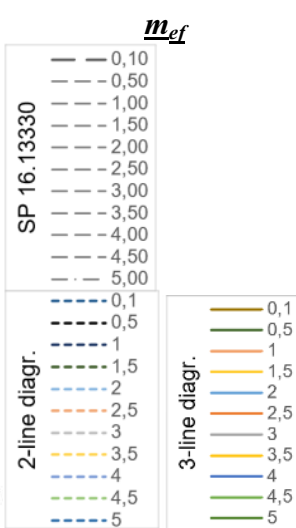

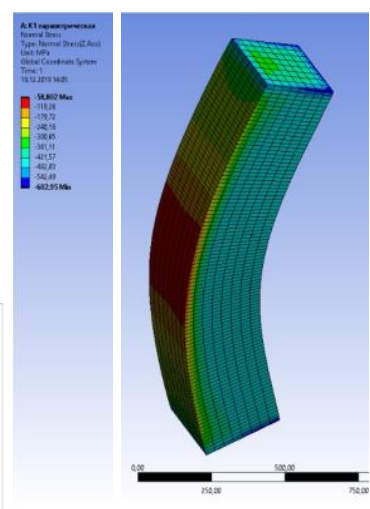

b)

Fig. 3. $\varphi_{e}$ curves for different eccentricity $m_{e f}(a)$, FE-model of rod with rectangular cross-section (b) 
When processing test results, the FE-models of rods (Figure 2d) with a three-line diagram of steel were also used. To verify the correctness of the obtained results of the FEcalculations, we compare deformations of columns during the tests and of FE-models. Figure $4 \mathrm{a}$ shows a graph of the average shortening $d L$ for the model groups K2 (SA bending) and K6 (WA bending). A graph of deflections $f$ in the plane of the moment action is also given. The steel's work is modeled according to its actual work diagram, approximated by a three-line diagram (Figure 4b). The results of the tests and the FEsimulation give a satisfactory convergence (about $1-2 \%$ ). The exception is the deflection of the K6.1 column, where the discrepancy was $34 \%$ at load stages 1-1.5 MN. At the same time, with a maximum load on the K6.1 column of $2.6 \mathrm{MN}$, the difference in deflections became no more than $7 \%$, which is also a satisfactory result. This is due to the presence of the initial skew of the load application and the initial operation of the rod according to the oblique bending scheme (when the random eccentricity along the two main planes of the rod was approximately equal).

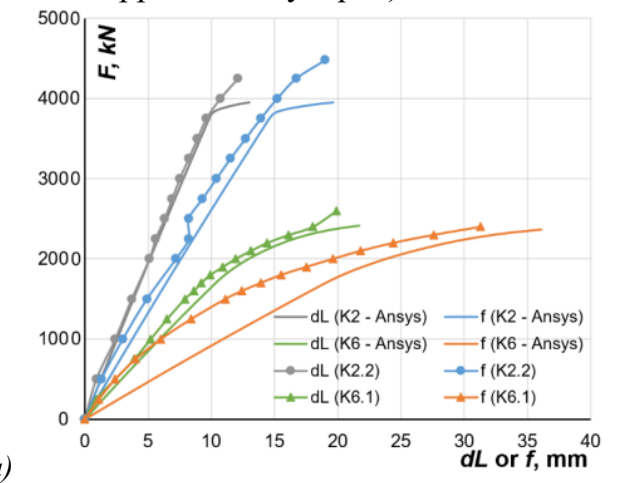

b)

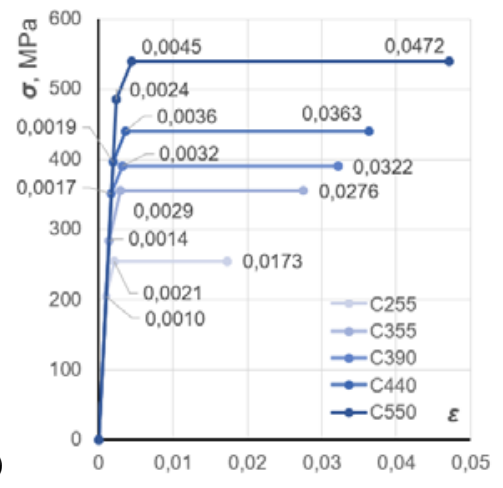

Fig. 4. Average deformation of $\mathrm{K} 2$ and $\mathrm{K} 6$ groups by test results and ANSYS calculations $(a)$, where $d L$ - shortening, $f$-deflection in the plane of bending moment; three-line diagram for FEmodel $(b)$

Table 2. Comparison of the results of tests and calculations of I-beam racks according to the standards and with FE-modelling

\begin{tabular}{|c|c|c|c|c|c|c|c|c|c|c|c|c|}
\hline No. & $\stackrel{n}{u}$ & $\bar{\lambda}$ & $m_{e f}$ & $\begin{array}{c}N_{S P} \\
\mathbf{k N}\end{array}$ & $\varphi_{e}$ & kN & $\varphi_{\text {test }}$ & $\begin{array}{l}N_{A} \\
\mathbf{k N}\end{array}$ & $\varphi_{A}$ & $\underset{\%}{\Delta_{1},}$ & $\begin{array}{c}\Delta_{2}, \\
\%\end{array}$ & $\begin{array}{c}\Delta_{3}, \\
\%\end{array}$ \\
\hline $.1,1.4$ & $\mathrm{SA}$ & .9 & 1 & v & 1 & 4473 & 0.45 & 4 & $0 .{ }^{2}$ & 1 & -4 & 7.8 \\
\hline $1,2.2$ & $\mathrm{SA}$ & 1.1 & 2.7 & os & 0.40 & 4395 & 0.44 & 4015 & 0.40 & 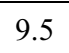 & 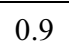 & 8.6 \\
\hline $.1,3.2$ & SA & 1.0 & 2.7 & 4061 & 0.41 & 441 & 0.44 & 408 & 0.41 & 7. & & 7.4 \\
\hline $4.1,4.2$ & SA & 1.1 & 2.7 & 32 & 0.4 & 4415 & 0.4 & 4032 & 0. & & & 8.7 \\
\hline $1,5.2$ & WA & 1.9 & 4.9 & 2266 & 0.23 & 2325 & 0.24 & 2465 & 0.25 & 2. & 8. & -6.0 \\
\hline $6.1,6.2$ & WA & 1.9 & 4.8 & 2325 & 0.23 & 2354 & 0.23 & 2466 & 0.24 & 1.0 & 8.0 & -4.8 \\
\hline \multicolumn{13}{|c|}{$\begin{array}{l}\text { Notes } \\
1 \text { The ultimate force } N_{S P} \text { and } \varphi_{e} \text { determined according to formula } 109 \mathrm{SP} 16.13330 .2017 \text {, paragraph } \\
9.2 .2 \text {, Tables D. } 2 \text { and D.3, as for cross-sections of types } 5 \text { and } 8, \text { respectively. } \\
2 \text { The following formulas are used: } \varphi_{\text {test }}=N_{\text {test }} / \sigma_{y} A, \varphi_{A}=N_{A} / \sigma_{y} A, \Delta_{1}=1-\varphi_{e} / \varphi_{\text {test }}, \Delta_{2}= \\
1-\varphi_{e} / \varphi_{A}, \Delta_{3}=1-\varphi_{A} / \varphi_{\text {test }} \text {, where: the values } N_{\mathrm{A}} \text { and } \varphi_{A} \text { are determined by FE-modelling } \\
\text { (ANSYS); } N_{\text {test }}-\text { is maximum load-bearing capacity determined by the test results; } \sigma_{y}-\text { yield } \\
\text { strength based on test results. }\end{array}$} \\
\hline
\end{tabular}

A comparison of test results and calculations for H-beams 40K2 (2016) is shown in Table 2. The calculations are performed in accordance with the standard Russian code 
methodology (SP 16.13330.2017) for the actual values of the yield strength of steels, as well as considering the actual dimensions of every cross-section with averaging over the height. Calculation results for corresponding rods in the ANSYS 2020 R2 are also presented there. Rods FE-modelling considers their actual dimensions, the boundary conditions during testing, the actual values of the material strength and parameters of the steel work diagram. FE-model appropriate K1.1 is shown on Figure 2d for example.

\subsection{Results analysis of other authors}

From the set of tests previously presented in section 2.2 of this article we have choose only those in which eccentricities are smaller than accidental eccentricity or practically zero. It was taken than accidental eccentricity no more than $i / 20+l / 750$, as it is specified in Russian codes (SP 16.13330.2017). This is a special case of eccentric compression, which in the Russian codes is called "central" compression. Out of 656 previously considered tests, only 184 can be attributed to this type. Of these: 30 pcs. - hollow sections (box, rolled or welded); 23 pcs. - solid cross-section (circle, rectangle); 134 pcs. - I- or H-beams of various configurations. Only $17 \%$ of $\mathrm{H}$-beams $(23 \mathrm{pcs}$.) were tested with small eccentricity in the plane of greater rigidity (SA) due to the complexity of the correct device of loosening in the plane of lower rigidity. Diagram (Figure 5a) shows the dependence of $\Delta_{\varphi}=\varphi_{e} / \varphi_{\text {test }}$ on relative slenderness $\bar{\lambda}=L / i \cdot \sqrt{R_{y} / E}$. It is found that: the maximum deviations occur in the range $\bar{\lambda}$ from 2 to 4 (near 3.14); the minimum deviations correspond to the minimum flexibility from 0.5 to 1.5 ; I-beams ( 34 pcs.) practically do not give outliers in the zone $\Delta_{\varphi}$ $>1$. That is, the existing formulas describe the work of these rods relatively well. H-beams (100 pcs.) have only $75 \%$ tests, which matched with codes calculations. Statistical processing of the obtained data shows that the formulas of SP 16.13330 for rods with "central" compression confirm the load-bearing capacity: in $80 \%$ of cases for I- and $\mathrm{H}$ beams (106 out of 134 tests); in $57 \%$ of cases for box sections (17 out of 30 tests); in $70 \%$ of cases for solid sections (16 out of 23 experiments).
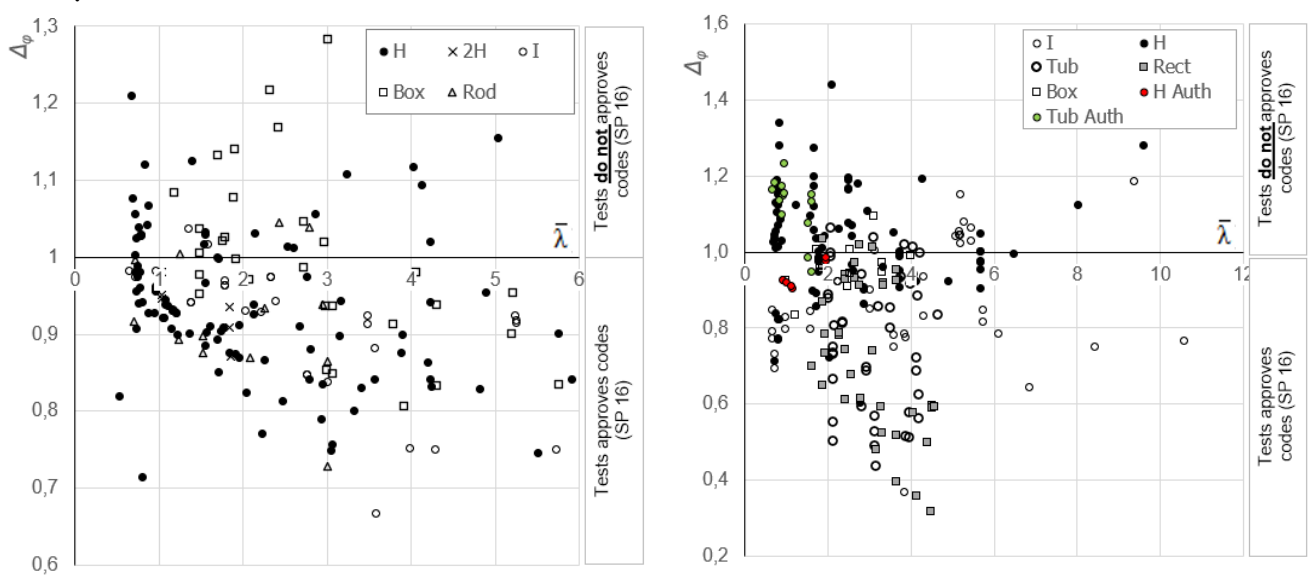

Fig. 5. Diagram of $\Delta_{\varphi}=\varphi_{e} / \varphi_{\text {test }}$ depends on slenderness (where $\varphi, \varphi_{e}$ calculated according to SP 16.13330 and $\varphi_{\text {test }}$ obtained from the test results): for rods without eccentricity (a), for rods with an eccentric compression $(b)$

For I- and H-beams, the best convergence between tests and "theoretical" calculations is obtained, since this type of cross-section is the most fully studied. Attention is drawn to the poor convergence of calculation results with test data for hollow box sections (rolled or welded). This effect is explained by the significant influence of residual welding stresses in boxes, as well as by the phenomena of riveting in the corners of bent sections. It is 
erroneous to attribute cold formed box-type cross-section to the most effective crosssections (curve $a$ in SP 16.13330). Box-section performance under an eccentrically load does not differ from the work of I- or H-beams in the plane of web. In this regard, it seems correct to assign such cold-formed sections to the type of curve $c$, as is done in the Eurocode 3.

Consider the rest of the tests that were not included in the analysis of the "central" compression - eccentrically compressed rods. If, out of the 656 tests presented, we discard those in which the destruction occurred due to local buckling, then only 234 tests remain. Of these, 90 and 38 tests will relate to I and H beams; 55 - to round pipes; 14 - to hollow square or rectangular sections; 37 -to solid rectangular ones. Diagram $\Delta_{\varphi}-\bar{\lambda}$ for the specified cases of eccentrically compression, see Figure $5 \mathrm{~b}$. The red and green dots on Figure $5 \mathrm{~b}$ show the tests performed by the author.

$92 \%$ of rods with a rectangular cross-section, $71 \%$ with a box-shaped one, and $71 \%$ of I-beams give good convergence with the norm methodology. That is, for the specified number of experiments, the destruction occurred much later than it turned out according to Russian codes. The calculation of pipes according to codes in $69 \%$ of cases gives a margin in comparison with the test results. Pipe rods, for which buckling occurred earlier than the limit according to the norms (31\%), collapsed according to the scheme of local buckling of the wall. This also applies to the tests conducted by the author (the green dots in Figure 5b). The results of analysis of the H-beams calculations show that only $47 \%$ of the test results meet the standard calculation method (see the black dots in Figure 5b). At the same time, it is noted that for $74 \%$ of the considered test results, the value of $\Delta_{\varphi}$ does not exceed 1.1 . That is, the code "overload" is no more than $10 \%$, which is covered by the existing partial reserve coefficients used in engineer calculations. Thus, it can be stated that the calculation method of the Russian codes needs to be clarified in terms of H-beams and pipes.

\section{Discussion}

Following generalizations can be made for H-beams tests (2016) and FE-modelling. The existing standard calculation method according to SP 16.13330 for eccentric compressed elements of low flexibility gives a margin of 7 to $9.5 \%$ for H-beams bent in the plane of greater rigidity (SA); for the plane of lower rigidity, the margin is from 1.3 to $2.4 \%$ (WA). The FE-calculation of models also gives a certain margin for calculating structures (from 0.1 to $8 \%$ ) compared to the standard method, even without considering residual stresses. The current technology of production of rolled I- and H-beams in Russia using steels with a yield strength of up to $500 \mathrm{MPa}$ practically does not affect the results of the design calculation. Therefore, the separation of high-strength steels into a separate curve, as suggested by foreign researchers, is premature in the author's opinion. To assess the effect of the I-beam manufacturing technology on the ultimate load-bearing capacity, it is necessary to experimentally study the values of residual stresses in rolled and welded profiles.

For spiral-welded and stright-welded pipes tests (2017) we can make following conclusions. The discrepancy between the results of the tests, numerical and normative (codes) calculations is revealed. In most cases, actual loss of stability (general or local) occurs earlier than it should occur by calculation. The largest discrepancy between test and code $(51 \%)$ was fixed in the thinnest $720 \times 7.5$ pipe with a significant load eccentricity. For the same pipe, the maximum difference between the results $(33 \%)$ of the tests and FEcalculation is noted. The model for which was created in the form of an ideal cylindrical shell without taking into account the initial local rotations of the pipe walls. It is noted that the deviation between code and FE-calculations with tests results increases with increasing thinness $(\mathrm{D} / \mathrm{t})$, eccentricity and yield strength. The steel diagram has a pronounced zone of 
elastic-plastic deformations and does not have a hardening area after reaching the conditional yield strength. A diagram of the "classical" type with a developed yielding cannot be obtained due to the method of pipe production. This should be considered when updating the codes for the calculation.

If we plot the $\Delta_{\varphi}-R_{y}$ graph (Figure 6) for the central and eccentric compression, we can see the following. Most cases that do not meet the standards for eccentric loading occur on racks with a yield strength of 200-270 MPa. This corresponds to the part of the tests of the early 20th century when the methods of verification of materials were not fully developed. The existing normative methodology of the Russian Codes satisfactorily describes the use of steels with a yield strength of up to $1000 \mathrm{MPa}$. That is, the Russian codes can be used in the calculation of such steels, but they will give some margin. For a more accurate calculation of the rods, a computer simulation should be performed considering the threeline diagram of the work of the steel and the residual stresses.
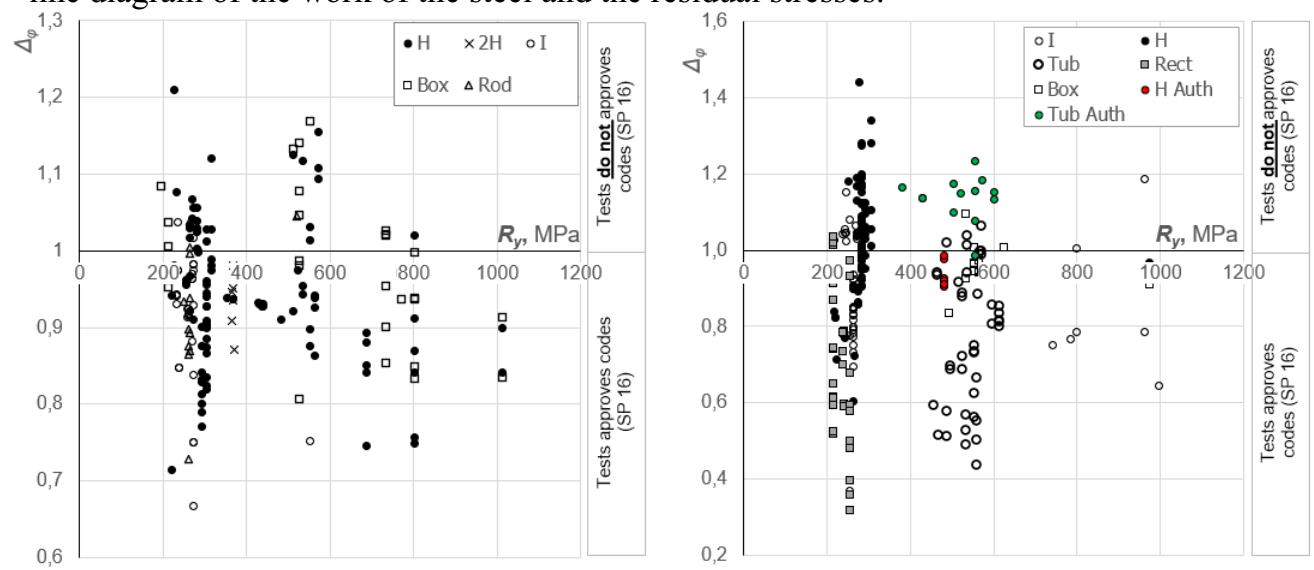

Fig. 6. Diagram of $\Delta_{\varphi}=\varphi_{e} / \varphi_{\text {test }}$ depends on yield strength $R_{y}$ (where $\varphi, \varphi_{e}$ calculated according to SP 16.13330 and $\varphi_{\text {test }}$ obtained from the test results): for rods without eccentricity $(a)$, for rods with an eccentric compression $(b)$

\section{Conclusions}

1) The results of more than 600 experiments on compressed rods over the past 100 years, including those performed at the TSNIISK, are considered, and summarized. The tests cover dimensionless slenderness from 0.5 to 5 and steels with a yield strength up to $1000 \mathrm{MPa}$.

2) Russian codes SP 16.13330 satisfactorily describe rods capacity under central and eccentric compression, including made of newest steels with a yield strength of up to 1000 $\mathrm{MPa}$. The formulas give some margin and should be refined with proper FE-modelling. The changes should relate to the refinement of the coefficient $\eta$, after the experimental determination of residual stresses (which have not been performed for Russian steels and rolled products since the 1970 s).

3) FE-modelling of compressed rods should be carried out considering the initial imperfections, residual stresses, as well as a three-line or curved steel diagram.

Acknowledgements. This work has been carried out with financial support from the Steel Construction Development Association (ARSS, Moscow, D. Eremeev). Samples for tests were given by EVRAZ Holding (K. Shvedov, K. Sokolov,). Special thanks to prof. I. Vedyakov, prof. P. Odessky, V. Artamonov, A. Olurombi, S. Konina, and A. Lushkin for assistance in this work. 


\section{References}

1. A.V. Gemmerling, The bearing capacity of compressed and compressed-curved elements of steel structures in Experimental studies of steel structures (collection of articles) under the editorship of V. A. Baldin, M.-L.: Gos. Ed. in the construction literature (1950), pp. 5-69 (in Russian)

2. A.V. Gemmerling, The bearing capacity of I-beam beams in Experimental studies of steel structures (collection of articles) under the editorship of V. A. Baldin, M.-L.: Gos. Ed. in the construction literature (1950), pp. 70-98 (in Russian)

3. N. P. Melnikov, V. M. Vakhurkin, G. M. Chuvikin Experimental and theoretical study of the general case of loss of stability of an out-of-center compressed I-beam rod (1st stage), M.: GPI Projectstalkonstruktsiya (1954), 387 p (in Russian)

4. G. E. Belsky, Theoretical and experimental studies of deformability and stability of elastically pinched rods in Calculation of structures working in the elastic-plastic stage (proceedings of the Institute), ed. by A.V. Gemmerling, M.: State Publishing House of the literature on construction, Architecture and building materials (1961), p. 125-238 (in Russian)

5. G. I. Bely, Spatial work and limit states of rod elements of metal structures: diss. ... doct. technical sciences: 05-23-01, L. (1987), 464 p (in Russian)

6. P. D. Odessky, D.V. Konin, S.M. Konina, K.N. Shvedov, K. E. Sokolov Hot-rolled products of high strength of I-beam profile with parallel faces of shelves for building structures of mass application in Steel, No. 6, (2017), pp. 56-63

7. I. I. Vedyakov, P.D. Odessky, D. V. Konin, A.A. Egorova, Steel for rolling I-beams with parallel faces of shelves in Industrial and civil construction (PGS), No. 6, (2015), p. $30-35$

8. D.V. Konin, Olurombi A.R. Stability analysis of straight-weld and spiral-weld pipes made of high-strength steels under central and off-centre compression on the example of full-scale experiments in Proceedings of higher educational institutions.

Construction, №6 (714), (2018), pp. 106-116

9. M. Ros, Die Bemessung zentrisch und exzentrich gedruckten Stabe auf Knickung in Bericht über die II Internationale Tagung für Brückenbau und Hochbau. - Wien: Springer-Verlag (1928), pp. 282-303 (in German)

10. A.H. Stang, H.L. Whittemore, L.R. Sweetman, Tests of Eight Large H-Shaped Columns Fabricated from Carbon-Manganese Steel in Journal of Research of National Bureau of Standards (1936), Vol. 16, pp. 595-626

11. B.G. Johnston, L.T. Cheney, Steel Columns of Rolled Wide-Flange Section Progress Report No.1 in AISC Research Report No. 190, Lehigh University (1942), 39 p.

12. L. T. Cheney, Short steel columns progress report in Fritz Laboratory Reports, Paper 1222, Lehigh University (1939), 27 p

13. B.G. Johnston, L.T. Cheney, Steel Columns of Rolled Wide-Flange Section Progress Report No.2 in AISC Research Report No. 191 (Nov. 1942), Lehigh University (1942) $39 \mathrm{p}$

14. G. M. Chuvikin, Experimental study of the stability of out-of-center compressed steel single-wall rods with biaxial eccentricity in Calculation of spatial structures, $\mathrm{M}$. (1960), Issue 5, pp. 57-78 (in Russian)

15. K. Kloppel, E. Winkelmann, Experimentelle und the oretische Untersuchungen uber die Traglast von zweichzig ausermitting gedruckten Stahlsaben in Der Stahlbau, (1962) №2-3, pp. 78-87 (in German) 
16. C. Birnstiel, J. Michalos, Ultimate load of H-columns under biaxial bending in A.S.C.E.: Structural Division Journal, (1963), Vol. 89, ST. (N) 2, pp. 161-197

17. E.P. Popov, R.M. Stephen, Capacity of Columns with Splice Imperfections in Engineering Journal. American Institute Of Steel Construction (1977), Q1, pp. 16-23.

18. G. E. Belsky, L. N. Dionisiadi, Investigation of the bearing capacity of ring-section rods in Steel structures in pipes. Experimental and theoretical research. Under the editorship of prof. S. A. Ilyasevich, M.: TSNIISK im. V. A. Kucherenko, (1973), pp. 84-92

19. A.M. Rivkin, G. E. Belsky, Study of stability of non-centrally compressed rods of tubular ring section made of steel 15GS in Steel structures in pipes. Experimental and theoretical research. Under the editorship of prof. S. A. Ilyasevich, M.: TSNIISK im. V. A. Kucherenko, (1973), pp. 92-106

20. T. Usami, Y. Fukumoto, Local and overall buckling of welded box columns in J. Struct. Div. 108 (ST3) (1982), pp. 525-542

21. T. Usami, Y. Fukumoto, T. Aoki, Tests on the interaction strength between local and overall buckling of welded box columns in 土木学会論文報告集 (Collection of reports of the Society of Civil Builders) (1981), №308, p.p. 47-58 (in Japanese)

22. T. Usami, Y. Fukumoto, Welded box compression members in Journal Struct. Eng.(1984), 110 (10), p.p. 2457-2470

23. K.J.R. Rasmussen, G.J. Hancock, Tests of high strength steel columns in J. Constr. Steel Res. 34 (1), (1995), pp. 27-52

24. G. Shi, H.Y. Ban, F.S.K. Bijlaard, Tests and numerical study of ultra-high strength steel columns with end restraints in J. Constr. Steel Res. 70, (2012), pp. 236-247

25. H.Y. Ban, G. Shi, Y.J. Shi, Y.Q. Wang Overall buckling behaviour of $460 \mathrm{MPa}$ high strength steel columns: experimental investigation and design method in J. Constr. Steel Res. 74, (2012), pp. 140-150

26. H.Y. Ban, G. Shi, Y.J. Shi, M.A. Bradford, Experimental investigation of the overall buckling behaviour of 960 MPa high strength steel columns in J. Constr. Steel Res. 88, (2013), pp. 256-266

27. Y.B. Wang, G.Q. Li, S.W. Chen, F.F. Sun, Experimental and numerical study on the behavior of axially compressed high strength steel columns with H-section in Eng. Struct., 43, (2012), pp. 149-159

28. G. E. Belsky, L. A. Gildengorn To the calculation of steel columns with a complex cross-section in Construction mechanics and calculation of structures, No. 6, (1981), pp. 68-73 (in Russian)

29. Y.B. Wang, G.Q. Li, S.W. Chen, F.F. Sun, Experimental and numerical study on the behaviour of axially compressed high strength steel box-columns in Eng. Struct. 58, (2014), pp. 79-91

30. Tian-Ji Li, Si-Wei Liu, Guo-Qiang Li, Siu-Lai Chan, Yan-Bo Wang Behaviour of Q690 high-strength steel columns: Part 1: Experimental investigation in Journal of Constructional Steel Research (2016), №123, pp. 18-30

31. F. Zhou, L.W. Tong, Y.Y. Chen Experimental and numerical investigations of high strength steel welded H-section columns in Int. J. Steel Struct. 13 (2), (2013), pp. 209218

32. S.D. Nie, S.B. Kang, L. Shen, B. Yang Experimental and numerical study on global buckling of Q460GJ steel box columns under eccentric compression in Eng. Struct. 142. (2017), pp. 211-222 